\title{
Subtype Variation Among Bacterial Endosymbionts of Tubeworms (Annelida: Siboglinidae) from the Gulf of California
}

\author{
ROBERT C. VRIJENHOEK ${ }^{1, *}$, MELISSA DUHAIME ${ }^{2}$, AND WILLIAM J. JONES ${ }^{1}$ \\ ${ }^{1}$ Monterey Bay Aquarium Research Institute, 7700 Sandholdt Road, Moss Landing, California 95039; \\ and ${ }^{2}$ Max Planck Institute for Marine Microbiology, Celsiusstrasse 1, D-28359, Bremen, Germany
}

Symbiosis involving chemoautotrophic bacteria allows vestimentiferan tubeworms to thrive in sulfidic marine environments. This study examined genetic variation among endosymbionts associated with three vestimentiferan species from the Gulf of California. Small subunit (16S) rRNA sequences identified two evolutionary lineages of $\gamma$-Proteobacteria in these worms. Phylotype-II bacteria associated with the hydrothermal vent species Riftia pachyptila exhibited no subtype variation upon examination of form II (cbbM) RuBisCO, whereas the phylotype-I bacteria associated with two cold-seep species, Escarpia spicata and Lamellibrachia barhami, were polymorphic. Bacterial subtypes distinguished by three RuBisCO alleles occurred at similar frequencies in both host species when sampled together from tubeworm clusters, offering, therefore, no evidence for host-specificity. Instead, the frequencies of these subtypes varied significantly among patchily distributed tubeworm clusters. Subtype variation on small spatial scales is consistent with prior evidence that vestimentiferans acquire their symbionts locally from the environment in which they settle as larvae.

Adult vestimentiferans are nourished by endosymbiotic bacteria that oxidize inorganic sulfides and fix carbon via the Calvin-Benson cycle (1). These essential bacteria infect vestimentiferans de novo in each generation by penetrating the epidermis of trochophore larvae that settle on benthic substrates (2). Previous studies (summarized in reference 3) revealed two related phylotypes (i.e., a clade defined by $16 \mathrm{~S}$ rRNA sequences) of $\gamma$-Proteobacteria associated with ves-

Received 18 January 2007; accepted 6 March 2007.

* To whom correspondence should be addressed. E-mail: vrijen@mbari.org Abbreviations: 16S, small-subunit ribosomal RNA; rbc, form II ( $c b b M)$ ribulose-1,5-bisphosphate carboxylase/oxygenase (RuBisCO); ST, Southern Trough; TF, Transform Fault. timentiferans worldwide. The two phylotypes segregate geographically and according to the kind of chemosynthetic habitat in which the hosts settle. Phylotype-I is found in cold-seep vestimentiferans worldwide and in hydrothermal vent vestimentiferans from the western Pacific. Phylotype-II has been found only in vestimentiferans from eastern Pacific hydrothermal vents.

When distinct vestimentiferan species co-occur in a habitat, they host the same symbiont phylotype. Conversely, when a single host species can occur in multiple habitats-as does Escarpia spicata, which is found at seeps, vents, and whale-falls-it acquires the symbiont phylotype associated with that habitat. Such "opportunistic environmental acquisition" of symbionts is hypothesized to be an ecologically flexible strategy that allows an invertebrate host to incorporate locally adapted microbial strains (4). Nonetheless, the ribosomal sequences defining these bacterial phylotypes are highly conserved and may not reveal subtype variation that is physiologically or ecologically relevant. Indeed, co-occurring vestimentiferan host species that share the same bacterial phylotype can exhibit distinct ITS sequences and rep-PCR fingerprints (3). Thus, some degree of host-recognition or specificity might exist among genetic strains of these bacterial phylotypes; alternatively, apparent subtype associations with host species might be a consequence of sampling hosts that obtained their symbionts in different places or times from a spatially patchy and temporally varying environment (3). The goal of this study was to examine how host-specificity and small-scale environmental patchiness affect the subtype composition of vestimentiferan symbionts.

Vestimentiferans were sampled with a robotic submersible from hydrothermal vent and cold-seep environments in the central Gulf of California (Fig. 1A; Table 1). We 

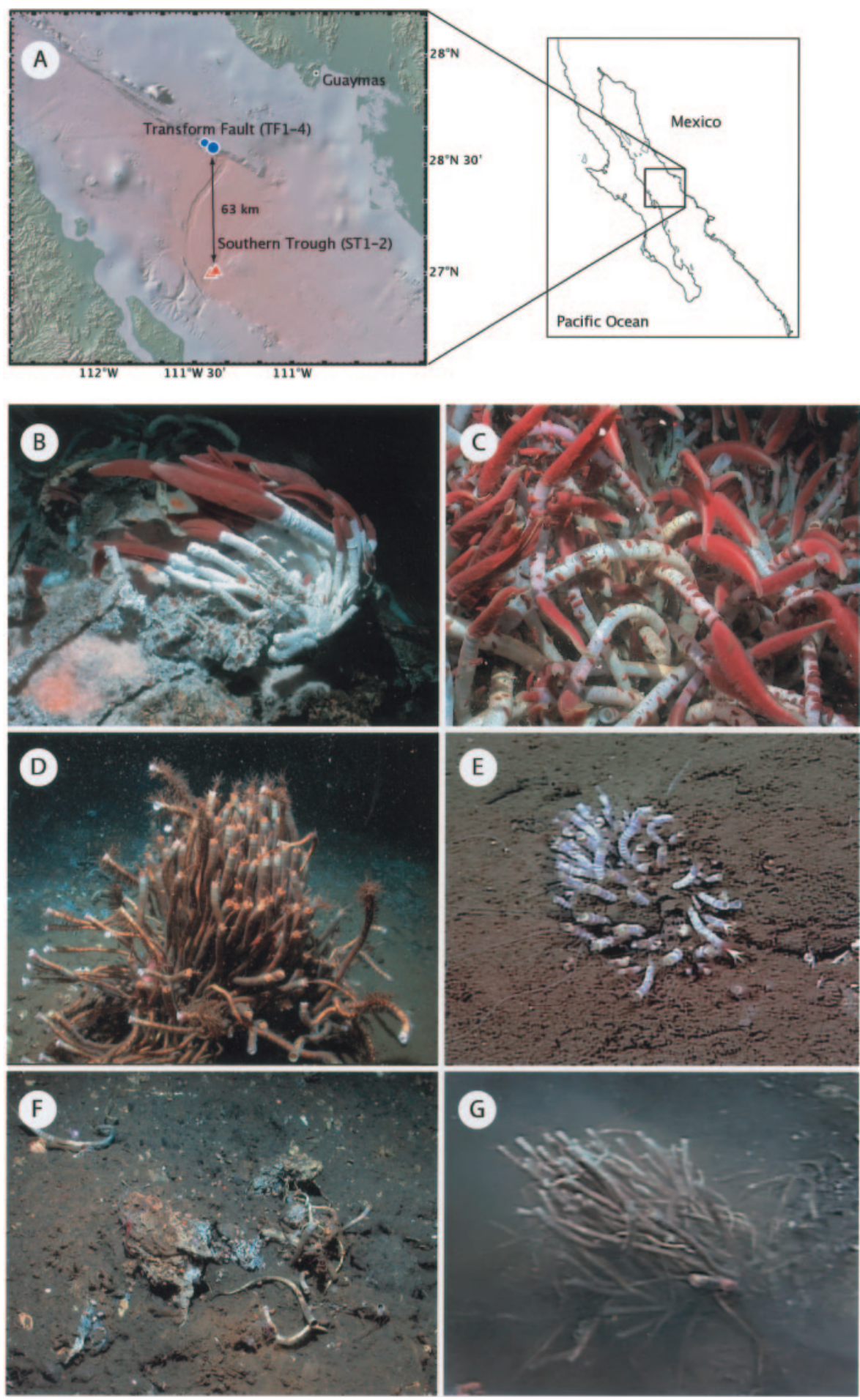

Figure 1. Vestimentiferan samples. (A) Gulf of California sample sites. (B) Site ST1: Riftia pachyptila in strong hydrothermal flow; maximum temperature $50{ }^{\circ} \mathrm{C}$ at base of worms; white Beggiotoa mats and Paralvinella grasslei (Annelida: Alvinellidae) on tubes. (C) Site ST2: R. pachyptila in diffuse hydrothermal flow; max. temp. $6{ }^{\circ}$ C; red Branchinotogluma grasslei (Annelida: Polynoidae) on tubes. (D) Site TF1: mixed cluster with Escarpia spicata (upright at center with notable spikes on obturacular cap) and Lamellibrachia barhami (lateral near base and lacking spikes); tubes encrusted with numerous hydroids. (E) Site TF2: cluster of small E. spicata (5-10 cm total length) with translucent tubes wrapped underneath sediment-covered carbonate rock. Due to its unusual appearance, most of this sample was preserved in $10 \%$ formalin as a potential voucher specimen. (F) Site TF3: loose aggregation of E. spicata and L. barhami in course sediments along a carbonate outcropping. (G) Site TF4: mixed cluster of E. spicata and L. barhami on carbonate sediments. 
Table 1

Tubeworm clusters from the Gulf of California; observed numbers of individual tubeworms hosting bacterial DNA sequences (16S and Rbc) are listed (in parentheses) for each genetic marker

\begin{tabular}{|c|c|c|c|c|c|c|c|c|}
\hline Sample & Fig. 1 & Latitude & Longitude & Depth (m) & Dive \# & Host & $16 S$ & $R b c$ (composition) \\
\hline ST1 & B & $27^{\circ} 00.648^{\prime}$ & $-111^{\circ} 24.430^{\prime}$ & 1992 & T549 & R. pachyptila & $I I(21)$ & $* d(21)$ \\
\hline ST2 & $\mathrm{C}$ & $27^{\circ} 00.660^{\prime}$ & $-111^{\circ} 24.419^{\prime}$ & 2000 & T551 & R. pachyptila & $I I(18)$ & $* d(18)$ \\
\hline TF1 & $\mathrm{D}$ & $27^{\circ} 34.665^{\prime}$ & $-111^{\circ} 27.009^{\prime}$ & 1779 & T548 & $\begin{array}{l}\text { L. barhami } \\
\text { E. spicata }\end{array}$ & $\begin{array}{l}I(16) \\
I(29)\end{array}$ & $\begin{array}{c}* a(1), * b(8), * a b(7) \\
* a(8), * b(9), * a b(12)\end{array}$ \\
\hline TF2 & E & $27^{\circ} 34.666^{\prime}$ & $-111^{\circ} 27.012^{\prime}$ & 1782 & T548 & E. spicata & $I(8)$ & $* a(8)$ \\
\hline TF3 & $\mathrm{F}$ & $27^{\circ} 34.668^{\prime}$ & $-111^{\circ} 27.012^{\prime}$ & 1778 & T548 & $\begin{array}{l}\text { L. barhami } \\
\text { E. spicata }\end{array}$ & $\begin{array}{l}I(2) \\
I(5)\end{array}$ & $\begin{array}{l}* a(2) \\
* a(5)\end{array}$ \\
\hline TF4 & G & $27^{\circ} 35.714^{\prime}$ & $-111^{\circ} 29.090^{\prime}$ & 1784 & T580 & $\begin{array}{l}\text { L. barhami } \\
\text { E. spicata }\end{array}$ & $\begin{array}{l}I(8) \\
I(4)\end{array}$ & $\begin{array}{l}{ }^{*} c(8) \\
{ }^{*} c(4)\end{array}$ \\
\hline
\end{tabular}

distinguished adult specimens of Riftia pachyptila Jones, 1981, Escarpia spicata Jones, 1985, and Lamellibrachia barhami Webb, 1969, morphologically $(5,6)$ and identified all small individuals ( $<5 \mathrm{~cm}$ total length) by their speciesdiagnostic mitochondrial COI sequences (for methods, see 7). To characterize the symbionts, we excised a small piece $\left(\sim 1 \mathrm{~cm}^{3}\right)$ of symbiont-bearing trophosome tissue from each worm and extracted total DNA with the DNeasy isolation kit (Qiagen Inc., Valencia, CA). PCR amplifications of $16 \mathrm{~S}$ followed an established protocol (8) based on eubacterialspecific primers (9). Subtype variation was identified with a segment ( $\sim 400 \mathrm{bp}$ ) of form II $c b b M$ RuBisCO that was amplified with primers designed for the $R$. pachyptila endosymbiont (10). Purification of PCR products and sequencing procedures followed protocols routinely employed in our laboratory (8).

We observed two bacterial phylotypes (GenBank acc. nos. DQ232901 and DQ232902) among the 16S sequences examined in this study. Phylotype-I and phylotype-II sequences differed at 54 nucleotide positions out of 1441 (3.76\% uncorrected $p$-distance). All $39 R$. pachyptila individuals from hydrothermal sites ST1 and ST2 hosted symbionts with a single $16 \mathrm{~S}$ sequence that was identical to previously reported phylotype-II sequences (U77478 and AY129116). In contrast, 46 individuals of E. spicata and 26 of L. barhami from cold-seep sites TF1 through TF4 hosted symbionts with a single $16 \mathrm{~S}$ sequence that was closely related to previously reported phylotype-I sequences (AY129091 and AY129106).

Four RuBisCo $(R b c)$ sequences (GenBank acc. nos. DQ232896-DQ232899) were observed among symbionts from these tubeworms (Table 2). All 39 phylotype-II symbionts from $R$. pachyptila possessed a single RuBisCO allele, $R b c^{*} d$ (Table 1$)$. In contrast, the phylotype-I symbionts from $L$. barhami and E. spicata were polymorphic for three alleles, $R b c^{*} a$, $* b$, and $* c$. DNA sequence divergence among the three alleles ranged from $5.9 \%$ to $8.4 \%$. The "4-gamete test" (11) showed no evidence for recombination. Divergence between the three phylotype-I alleles and the single phylotype-II allele was considerably greater, ranging from $20.7 \%$ to $23.4 \%$.

Frequencies of bacterial subtypes marked by these $R b c$ alleles varied among the cold-seep samples (Table 1). Symbionts from a sample of 12 worms (TF4) possessed the $R b c^{*} c$ allele, which was not found in samples $3.9 \mathrm{~km}$ to the south. Samples TF1, TF2, and TF3 were located along a $15-\mathrm{m}$ segment of a low-profile carbonate ridge. TF2 and TF3 were $10 \mathrm{~m}$ apart, and all 23 worms possessed symbionts with only the $R b c^{*} a$ allele. Just $5 \mathrm{~m}$ from TF2, the largest sample, TF1, was polymorphic: 9 worms possessed symbionts with $R b c^{*} a$; 17 worms hosted $R b c^{*} b$; and 19 worms hosted what appeared to be "mixed" $R b c * a b$ infections. Sequence traces of these putatively mixed infections exhibited two overlapping peaks at all the nucleotide positions that distinguished $R b c^{*} a$ and $* b$. To rule out contamination, we purified and amplified DNA again from 29 worms. The mixed-sequence traces were repeated from each of the original 19 putatively mixed infections. We similarly verified that 10 of the putatively pure infections could be repeated. In addition, we re-examined six worms by cloning (AmpliTaq Gold and Invitrogen TOPO kits) and sequencing 16 clones per worm. Three worms with putatively mixed infections produced clones in the following proportions: worm\#1 had $5 R b c * a+11 R b c * b$, worm\#2 had $7 R b c * a+$ $9 R b c * b$, and worm\#3 had $10 R b c * a+6 R b c * b$. No additional sequence variants or recombinants were identified among the 48 clones. We similarly examined three individuals that hosted putatively pure infections: two with $R b c * a$ and one with $R b c * b$. The original sequences were verified, and no additional sequences were found among the 48 clones. Analysis of this subset of worms provided confidence that subtype scores assigned from original sequence traces were accurate.

$R b c$ subtypes from the cold-seep samples did not segregate according to host species. TF1 was the largest sample, with 16 L. barhami and 29 E. spicata (Table 1). A $2 \times 3$ $G$-test analysis of independence (12, pp. 585-601) revealed that symbiont composition was independent of host species 


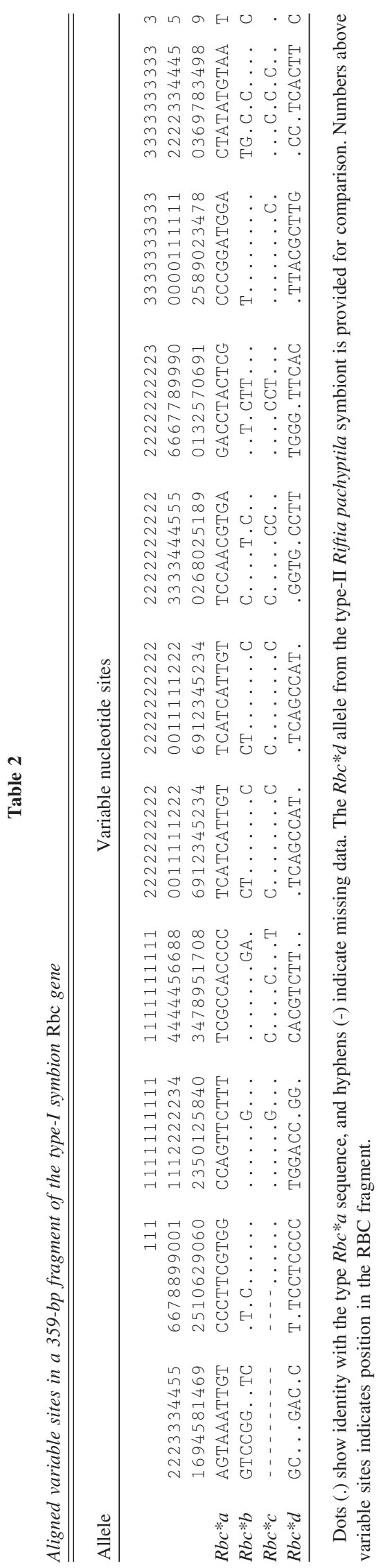

in the TF1 sample ( $G=3.78$, df $=2, P=0.15)$. The other samples were small and contained only one symbiont subtype each. It was possible, however, to simultaneously examine associations among symbionts $(S)$, host species $(H)$, and environmental patches $(E)$ with a three-way contingency analysis involving all four of the cold seep samples (13). A strong three-way interaction (HSE; $P<0.0001)$ confounded two-way tests in the combined sample: symbiont subtypes were highly significantly different among sample patches $(S E ; P<0.0001)$, and frequencies of the host species were marginally different among patches $(H E ; P=$ 0.0536). Isolating the common patch effects $(E)$ left no host-by-symbiont association $[H S(E) ; P=0.9868]$, and isolating symbiont subtype effects $(S)$ left no host-by-patch association $[H E(S) ; P=1.000]$. In contrast, isolating host effects did not eliminate the strong interaction between symbionts subtypes and sample patches $[\operatorname{SE}(H) ; P<$ 0.0001]. Thus, symbiont subtype composition of the cold seep tubeworms clearly varied across environmental patches but not as a result of associations with particular host species.

Hydrothermal vent and cold-seep vestimentiferans from the Gulf of California differed markedly in the amount of subtype variation contained in their associated endosymbionts. $R$. pachyptila hosted phylotype-II endosymbionts marked by a single RuBisCO subtype $(R b c * d)$. No subtype variation was found between $R$. pachyptila patches $50 \mathrm{~m}$ apart (ST1 and ST2), even though the patches differed in hydrothermal flow regimes, temperature, and associated biological communities (Fig. 1B, C). In contrast, the phylotype-I endosymbionts associated with $E$. spicata and $L$. barhami from cold seeps could be partitioned into three subtypes marked by $R b c$ alleles. Frequencies of the symbiont subtypes varied significantly among four samples of these worms collected from discrete tubeworm patches. No subtypes were shared between patches $3.9 \mathrm{~km}$ apart, and significant shifts in subtype frequencies existed between patches only $5 \mathrm{~m}$ apart. Nonetheless, no significant association existed between symbiont subtypes and host species within or across the four cold-seep samples. Apparently, $E$. spicata and $L$. barhami acquire symbionts in the same proportions, as expected if infections occur randomly following settlement of worm larvae in a particular environmental patch (2).

Very few studies have surveyed microbial diversity on comparably small scales (14, and references therein). Nevertheless, adaptive differentiation might operate at such scales. The fitness of Bacillus strains decays exponentially when strains are grown in soil extracts taken only a few meters from their home site (14). Microbial dispersal appears to be limited in aquatic systems (15), which should facilitate local differentiation that is driven by random drift or natural selection. Limited dispersal ability appears to be a favored hypothesis for genetic subdivision in a number of 
free-living microbes $(16,17)$. Although vestimentiferan symbionts possess genes for a functional flagellum that might contribute to motility of a free-living stage (18), the present evidence does not suggest effective dispersal of strains marked by these RuBisCO alleles. Unfortunately, very little is known about free-living forms of these microbes and where they live, on substrates or in the water column. For now we can only hypothesize that local-scale adaptive pressures, low dispersal rates, or both factors drive the observed scale of genetic differentiation among these symbiotic microbes.

\section{Acknowledgments}

We thank the pilots and crews of the ROV Tiburon and RV Western Flyer for their expert help, and our colleague C. Paull for providing sample TF4. Supported by grants from the David and Lucile Packard Foundation and the US National Science Foundation (OCE0241613).

\section{Literature Cited}

1. Felbeck, H. 1981. Chemoautotrophic potential of the hydrothermal vent tube worm, Riftia pachyptila Jones (Vestimentifera). Science 213: 336-338.

2. Nussbaumer, A. D., C. R. Fisher, and M. Bright. 2006. Horizontal endosymbiont transmission in hydrothermal vent tubeworms. Nature 441: $345-348$.

3. Di Meo, C. A., A. E. Wilbur, W. E. Holben, R. A. Feldman, R. C. Vrijenhoek, and S. C. Cary. 2000. Genetic variation among endosymbionts of widely distributed vestimentiferan tubeworms. Appl. Environ. Microbiol. 66: 651-658.

4. Won, Y.-J., S. J. Hallam, G. D. O'Mullan, I. L. Pan, K. R. Buck, and R. C. Vrijenhoek. 2003. Environmental acquisition of thiotrophic endosymbionts by deep-sea mussels of the genus Bathymodiolus. Appl. Environ. Microbiol. 69: 6785-6792.

5. Webb, M. 1969. Lamellibrachia barhami, gen. nov., sp. nov. (Pogonophora), from the northeast Pacific. Bull. Mar. Sci. 19: 18-47.
6. Jones, M. L. 1985. On the Vestimentifera, new phylum: six new species, and other taxa, from hydrothermal vents and elsewhere. Bull. Biol. Soc. Wash. 6: 117-158.

7. Black, M. B., K. M. Halanych, P. A. Y. Maas, W. R. Hoeh, J. Hashimoto, D. Desbruyères, R. A. Lutz, and R. C. Vrijenhoek. 1997. Molecular systematics of vestimentiferan tube worms from hydrothermal vents and cold-water seeps. Mar. Biol. 130: 141-149.

8. Goffredi, S. K., V. J. Orphan, G. W. Rouse, L. Jahnke, T. Embaye, K. Turk, R. Lee, and R. C. Vrijenhoek. 2005. Evolutionary innovation: a bone-eating marine symbiosis. Environ. Microbiol. 7: 13691378.

9. Lane, D. J., W. G. Weisberg, S. M. Barns, and D. A. Pelletier. 1991. 16 S ribosomal DNA amplification for phylogenetic study. J. Bacteriol. 173: $697-703$

10. Elsaied, H., and T. Naganuma. 2001. Phylogenetic diversity of ribulose-1,5-bisphosphate carboxylase/oxidase large-subunit genes from deep-sea microorganisms. Appl. Environ. Microbiol. 67: 17511765.

11. Hudson, R. R., and N. L. Kaplan. 1985. Statistical properties of the number of recombination events in the history of a sample of DNA sequences. Genetics 111: 147-164.

12. Sokal, R. R., and F. J. Rohlf. 1995. Biometry. Freeman, New York.

13. Lowry, R. 1998-2006. VassarStats: Web Site for Statistical Computation. [Online]. Available: http://faculty.vassar.edu/lowry/VassarStats. html (accessed 13 April 2007).

14. Belotte, D., J.-B. Curien, R. C. Maclean, and G. Bell. 2003. An experimental test of local adaptation in soil bacteria. Evolution 57: 27-36.

15. Harvey, R. W., and S. P. Garabedian. 1991. Use of colloid filtration theory in modeling movement of bacteria through a contaminated sandy aquifer. Environ. Sci. Technol. 25: 178-185.

16. Whitaker, R. J., D. W. Grogan, and J. W. Taylor. 2003. Geographic barriers isolate endemic populations of hyperthermophilic Archaea. Science 301: 976-978.

17. Papke, R. T., N. B. Ramsing, M. M. Bateson, and D. M. Ward. 2003. Geographical isolation in hot spring cyanobacteria. Environ. Microbiol. 5: 650-659.

18. Millikan, D. S., H. Felbeck, and J. L. Stein. 1999. Identification and characterization of a flagellin gene from the endosymbiont of the hydrothermal vent tubeworm Riftia pachyptila. Appl. Environ. Microbiol. 65: 3129-3133. 